in vivo $34: 321-330(2020)$

doi:10.21873/invivo.11777

\title{
A Clinicopathological Analysis of S100A14 Expression in Colorectal Cancer
}

\author{
ANGELA DIAMANTOPOULOU ${ }^{1 *}$, DIMITRIOS MANTAS ${ }^{1 *}$, IOANNIS D. KOSTAKIS ${ }^{1 *}$, \\ GEORGE AGROGIANNIS $^{2}$, ZOE GAROUFALIA $^{1}$, NIKOLAOS KAVANTZAS ${ }^{2}$ and GREGORY KOURAKLIS ${ }^{1}$ \\ ${ }^{1}$ Second Department of Propaedeutic Surgery, "Laiko" General Hospital, \\ National and Kapodistrian University of Athens, Medical School, Athens, Greece; \\ ${ }^{2}$ First Department of Pathology, National and Kapodistrian University of Athens, \\ Medical School, Athens, Greece
}

\begin{abstract}
Background/Aim: The calcium-binding protein S100A14 is involved in processes related to tumorigenesis and tumor propagation, such as proliferation, apoptosis, motility and invasiveness. Our aim was to investigate its role in colorectal cancer. Patients and Methods: One hundred and seven patients (65 men and 42 women) were included in this study. They had been diagnosed with colorectal cancer and undergone complete resection of their primary tumor. Tissue samples from archival blocks of their normal and malignant colorectal tissues were used for immunohistochemical assessment of S100A14 expression. S100A14 levels were evaluated using image analysis and associated with various clinicopathological parameters and prognosis. Results. S100A14 expression was reduced in malignant tissues when compared to normal intestinal mucosa in cases of T3-T4 tumors ( $p=0.017)$. Moreover, as far as S100A14 levels in malignant tissues are concerned, they were lower in T3-T4 tumors $(p=0.001), N 2$ disease $(p=0.034)$ and M1 disease $(p=0.019)$. Finally, very high $S 100 A 14$ production $\left(>75^{\text {th }}\right.$ percentile) was associated with shorter disease-specific $(H R=3.584, p=0.045)$ and relapse-free survival $(H R=4.527$, $p=0.007)$ in multivariate survival analysis. Conclusion: S100A14 expression is decreased in advanced colorectal cancer. However, cases with very high S100A14 levels have a worse survival.
\end{abstract}

This article is freely accessible online.

*These Authors contributed equally to this work.

Correspondence to: Ioannis D. Kostakis, MD, MSc, Ph.D., 27 Achridos Street, Kato Patissia, 11144 Athens, Greece. Tel: +30 2102230855, Fax: +30 2103813822, e-mail: i.d.kostakis@gmail.com

Key Words: S100A14, colorectal cancer, large intestine, immunohistochemistry.
S100 proteins constitute a family of 25 calcium-binding proteins, which in turn is member of the superfamily of EFhand proteins. S100 proteins form homodimeric or heterodimeric complexes with each other (1-9). When they bind calcium, they undergo conformational changes, which allow them to interact with other proteins $(1,2,4-6)$. Some of the S100 proteins have intracellular effects, while others have extracellular effects. However, there are also S100 proteins which exert both intracellular and extracellular effects (1-6). S100 proteins are involved in a number of regulatory mechanisms and pathways, affecting calcium homeostasis, metabolism, proliferation, apoptosis, migration, differentiation, inflammation, etc., through interactions with enzymes, receptors, cytoskeleton, transcription factors and nucleic acids in an autocrine and/or paracrine manner $(1,2,6-8)$. Thus, these proteins are part of many tumorigenic processes, such as cell motility and invasion, cell growth and cell death, interactions with tumor microenvironment, etc. (1-8).

One of the least studied members of this family is the S100A14 protein. It consists of 104 amino acids and the corresponding gene is located in the human chromosome 1q21, where most of S100 genes are also located. S100A14 is present in several human tissues of epithelial origin, with the highest expression detected in colon (10). Several studies have tried to assess the role of S100A14 in a number of malignant diseases, such as breast, ovarian or gastric cancer $(2,6)$. Nevertheless, very little is known about its role in colorectal cancer. Our aim was to investigate the expression of S100A14 in colorectal cancer and its associations with various clinicopathological parameters and prognosis.

\section{Patients and Methods}

Patients and tissue samples. One hundred and seven consecutive patients (65 men and 42 women) with a newly-diagnosed colorectal adenocarcinoma were included in this study. The patients had undergone complete excision of their primary tumor within a time period of 30 months (September 2008-March 2011). 
Data concerning survival and the first disease recurrence were collected retrospectively, in January 2017. Their mean age was 71.1 years $(\mathrm{SD}=10.2)$ and their median age was 73 years $(\mathrm{min}-$ max: 42-90). Patients were excluded if they had a medical history of a previously treated colorectal cancer or if they had received neoadjuvant treatment. Two formalin-fixed, paraffin-embedded archival blocks were obtained for each patient, with the first containing normal intestinal tissue and the second containing malignant intestinal tissue. Two additional blocks, one with normal liver tissue and the other with tissue from liver metastasis, were also obtained in three cases of synchronous resection of hepatic metastases. Tumor classification was performed using the criteria of the World Health Organization (11) and tumor staging was done according to the 8 th edition of the TNM Classification of Malignant Tumors according to the International Union Against Cancer (UICC) (12). Patients' clinicopathological data are listed in Table I. Our study was approved by the Ethical Committee of the "Laiko" General Hospital and it conforms to the Declaration of Helsinki.

Immunohistochemistry. All surgical specimens had been placed into $10 \%$ formalin solution immediately after their resection. All tissue samples had been processed using consecutively a graded series of alcohols, xylene and paraffin within $24 \mathrm{~h}$. Four $\mu \mathrm{m}$ thick sections were cut from the archival blocks for our study. They were deparaffinized and rehydrated using xylene, graded series of ethanol and distilled water. A citrate buffer (pH: 6.0) was applied on them in a microwave oven for $10 \mathrm{~min}$ for antigen retrieval. Subsequently, the slides were treated with $3 \%$ hydrogen peroxide for $15 \mathrm{~min}$ for blocking endogenous peroxidase activity, with $1 \%$ rabbit serum in PBS for $10 \mathrm{~min}$ for cell permeabilization and with 5\% rabbit serum in PBS for 30 minutes for blocking non-specific binding. A rabbit polyclonal antibody against human S100A14 protein (Novus Biologicals, Centennial, CO, USA) was diluted 1:2,000 using 1\% rabbit serum in PBS and applied on the slides, which were incubated overnight at $4^{\circ} \mathrm{C}$ afterwards. On the next day, the slides were treated with drops of Link $(150 \mu \mathrm{l})$, drops of Streptavidin (150 $\mu \mathrm{l})$ and a substrate-chromogen [3,3'diaminobenzidine (DAB)] solution for 1 hour each, consecutively. After treating the slides with PBS and distilled water, hematoxylin was then applied on them for 5 min. Finally, ethanol and xylene was added for tissue dehydration and the slides were mounted and coverslipped with an aqueousbased mounting medium.

Image analysis. Image analysis was performed within one month after immunohistochemistry. Five randomly sampled optical fields of intestinal mucosa, either normal or malignant, were selected from each slide and photographed under 400x original magnification. A digital camera (Nikon DS-2 MW, Nikon, Tokyo, Japan) attached to a light microscope (Nikon Eclipse 80i, Nikon, Tokyo, Japan) was used for this purpose. Images were stored as JPEG files and their analysis was done using the Image Pro Plus 5.1 software (Media Cybernetics, Bethesda, MD, USA). S100A14 expression was indicated as brown DAB staining, which was considered positive, whereas the blue hematoxylin counterstain was considered negative. The average intensity levels of brown staining [measured on a linear scale from 0 (representing black) to 255 (representing white)] and the average percentage of extent of brown staining were taken into consideration for each slide. The following equation was formed:
Table I. Clinicopathological data of patients with colorectal cancer $(N=107)$.

\begin{tabular}{|c|c|}
\hline Parameter & Number \\
\hline \multicolumn{2}{|l|}{ Gender } \\
\hline Male & 65 \\
\hline Female & 42 \\
\hline \multicolumn{2}{|l|}{ Age (years) } \\
\hline Mean \pm SD & $71.1 \pm 10.2$ \\
\hline Median (min-max) & $73(42-90)$ \\
\hline \multicolumn{2}{|c|}{ Segment of the large intestine } \\
\hline Right colon & 31 \\
\hline Left colon & 36 \\
\hline Rectum & 40 \\
\hline \multicolumn{2}{|l|}{ Tumor diameter $(\mathrm{cm})$} \\
\hline Mean \pm SD & $4.4 \pm 2$ \\
\hline Median (min-max) & $4(0.7-12)$ \\
\hline \multicolumn{2}{|l|}{ Stage } \\
\hline 0 & 6 \\
\hline I & 19 \\
\hline II & 28 \\
\hline III & 38 \\
\hline IV & 16 \\
\hline \multicolumn{2}{|l|}{$\mathrm{T}$} \\
\hline Tis & 6 \\
\hline $\mathrm{T} 1$ & 8 \\
\hline $\mathrm{T} 2$ & 22 \\
\hline $\mathrm{T} 3$ & 56 \\
\hline $\mathrm{T} 4$ & 15 \\
\hline \multicolumn{2}{|l|}{$\mathrm{N}$} \\
\hline No & 57 \\
\hline N1 & 24 \\
\hline $\mathrm{N} 2$ & 26 \\
\hline \multicolumn{2}{|l|}{ M } \\
\hline M0 & 91 \\
\hline M1 & 16 \\
\hline \multicolumn{2}{|l|}{ Grade } \\
\hline Low grade & 80 \\
\hline High grade & 27 \\
\hline \multicolumn{2}{|c|}{ Lymphovascular invasion } \\
\hline No & 80 \\
\hline Yes & 27 \\
\hline \multicolumn{2}{|l|}{ Perineural invasion } \\
\hline No & 98 \\
\hline Yes & 9 \\
\hline \multicolumn{2}{|c|}{ Mucinous adenocarcinoma } \\
\hline No & 99 \\
\hline Yes & 8 \\
\hline
\end{tabular}

T: Direct extent of the primary tumor, $\mathrm{N}$ : degree of disease spread to regional lymph nodes, M: distant metastases.

S100A14 expression $=(255$-average intensity levels of brown staining) $\mathrm{x}$ average percentage of extent of brown staining.

The average values for each slide were the mean intensity levels of brown staining and the mean percentage of extent of brown staining for the photographed optical fields.

Statistical analysis. The Shapiro-Wilk test was used for the assessment of normality of data distribution. Comparisons between 


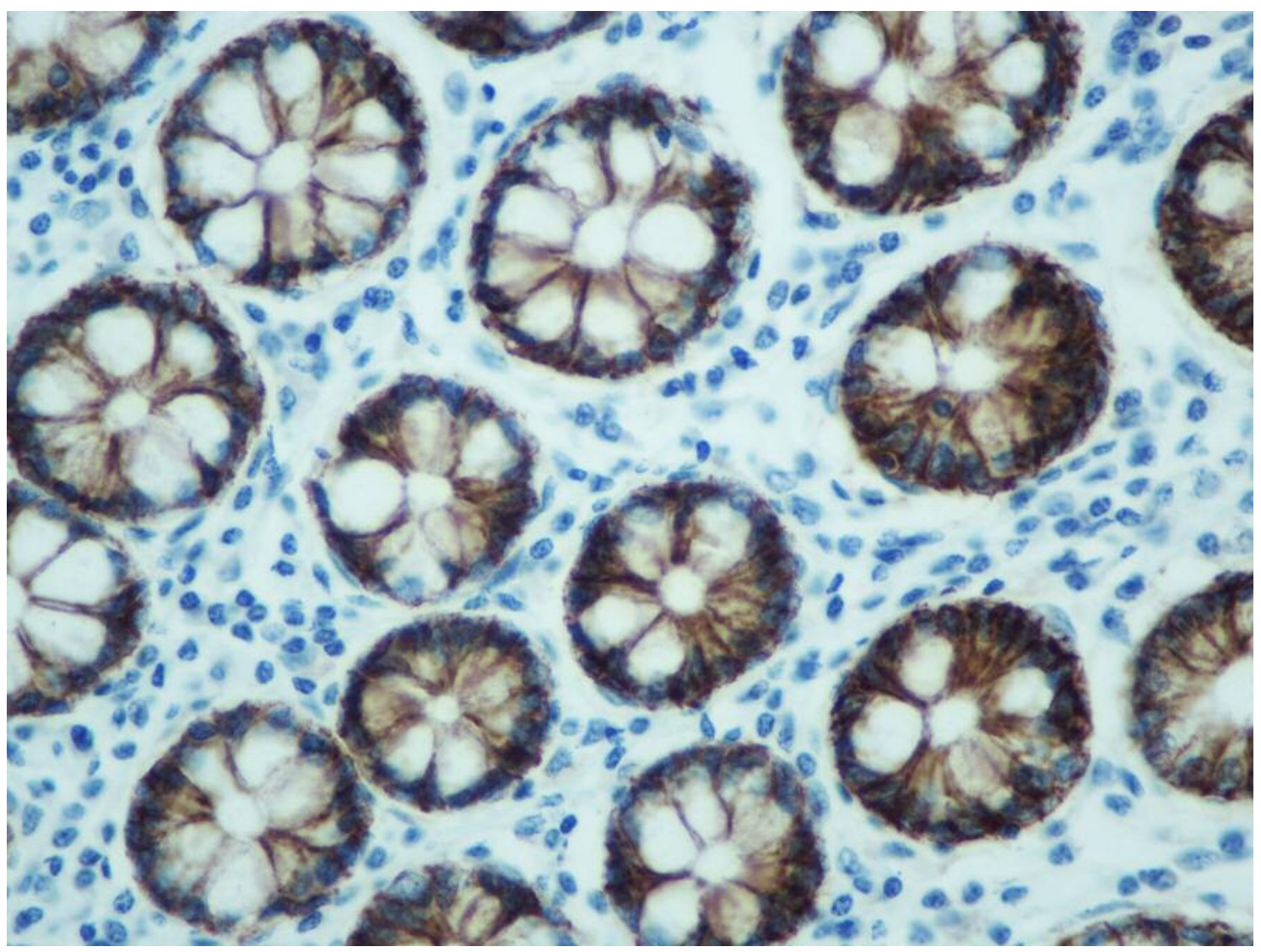

Figure 1. 3,3'diaminobenzidine (DAB) staining, representing S100A14 expression, in normal intestinal mucosa (400x original magnification).

two groups were made using the Student's $t$-test, the Welch test or the Mann-Whitney U test, as appropriate. Comparisons among three or more groups were made using the analysis of variance (ANOVA) with the Bonferroni correction or the Kruskal-Wallis test with the Bonferroni correction, as appropriate. The comparisons between normal and malignant tissues and between primary tumors and liver metastases were performed with the paired $t$-test or the Wilcoxon signed rank test, as appropriate. Correlations between two quantitative variables were assessed with the Pearson's correlation coefficient or the Spearman's rank correlation coefficient, as appropriate.

The patients were also divided into four groups according to S100A14 levels in the malignant intestinal mucosa for the assessment of the disease-specific survival (DSS) and the relapse-free survival (RFS) [group 1: $\leq 25^{\text {th }}$ percentile (S100A14 expression score: 38.5 ), group 2: $>25^{\text {th }}$ and $\leq 50^{\text {th }}$ percentile (S100A14 expression score: 45.5 ), group 3: $>50^{\text {th }}$ and $\leq 75^{\text {th }}$ percentile (S100A14 expression score: 50.6 ), group 4: $>75^{\text {th }}$ percentile]. Kaplan-Meier curves were used for the assessment of DSS and RFS and the comparisons among different groups regarding survival were made with the log-rank test. Multivariate survival analysis was performed using the Cox regression with the forward conditional method.

All the tests were two-tailed. The results were considered statistically significant if the $p$-value was less than 0.05 . The statistical analysis was carried out using the $25^{\text {th }}$ edition of the Statistical Package for the Social Sciences (SPSS) (IBM, Armonk, NY, USA).

\section{Results}

Comparison between normal and the malignant intestinal mucosa regarding S100A14 expression. S100A14 expression was detected in the cytoplasm of intestinal epithelial cells (normal or malignant) (Figures 1 and 2). In addition, weak S100A14 expression was observed in the cytoplasm of hepatocytes (Figure 3). When taking all cases together into consideration, there was no significant difference between normal [median score (min-max): 46.2 (13.1-66.9)] and malignant [median score (min-max): $44.6 \quad(21.2-74.8)]$ intestinal mucosa concerning S100A14 levels $(p=0.142)$. However, we tried to identify subgroups of patients in which S100A14 expression was altered in the malignant tissues. Thus, we observed that S100A14 production was reduced in malignant tissues (mean score \pm SD: $42.1 \pm 10.2$ ) in comparison with normal ones (mean score \pm SD: 45.9 \pm 8.4 ) in case of T3$\mathrm{T} 4$ tumors $(p=0.017)$.

Associations of S100A14 expression in the normal intestinal mucosa with gender, age and segment. There was no significant difference between men and women $(p=0.98)$ or 


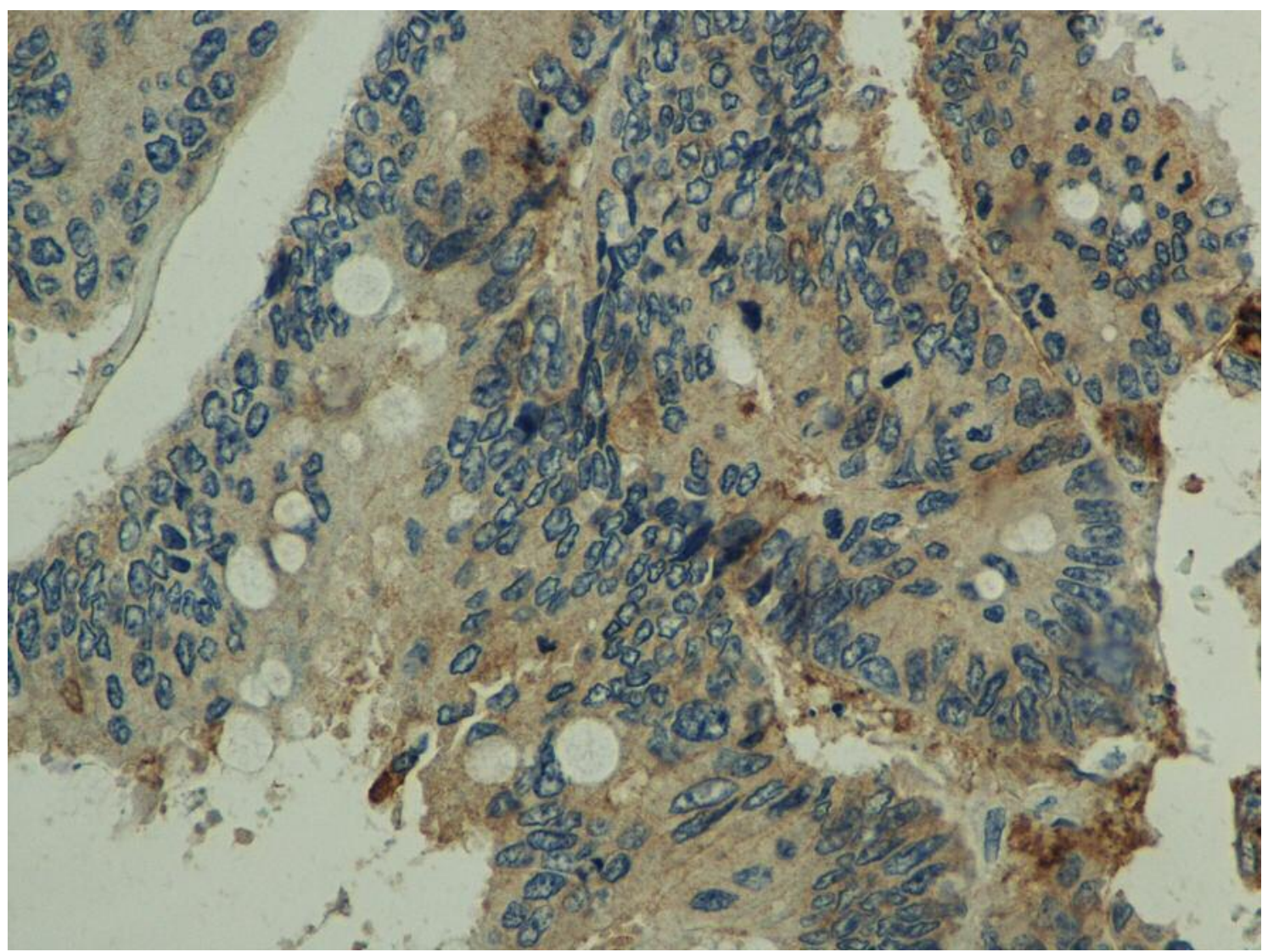

Figure 2. 3,3'diaminobenzidine (DAB) staining, representing S100A14 expression, in colorectal cancer (400x original magnification).

between older ( $>65$ years) and younger ( $\leq 65$ years) patients $(p=0.24)$ regarding S100A14 expression in the normal intestinal mucosa. Moreover, no actual correlation was detected between age and S100A14 levels in the normal intestinal mucosa $(\mathrm{r}=0.162, p=0.1)$. Finally, $\mathrm{S} 100 \mathrm{~A} 14$ production in the right part of the large intestine (taking the left colic flexure as a boundary) did not seem to differ from that in the left part $(p=0.446)$. Table II summarizes the aforementioned results.

Associations of S100A14 expression in the malignant tissue with various clinicopathological parameters. S100A14 expression in malignant tissues was lower in T3-T4 tumors when compared with Tis-T2 tumors $(p=0.001)$. Furthermore, S100A14 levels were lower in $\mathrm{N} 2$ disease in comparison with $\mathrm{N} 0-\mathrm{N} 1$ disease $(p=0.034)$. However, no significant correlation was detected between the exact number of infiltrated lymph nodes and S100A14 levels $(\mathrm{r}=-0.13, p=0.181)$. In addition, S100A14 production was decreased in M1 disease when compared to M0 disease $(p=0.019)$. On the contrary, S100A14 expression did not vary significantly in terms of gender $(p=0.963)$, age ( $\leq 65$ years versus $>65$ years) $(p=0.694)$, segment of large intestine (right versus left) $(p=0.254)$, tumor diameter $(\leq 4 \mathrm{~cm}$ versus $>4 \mathrm{~cm})$ ( $p=0.912)$, grade (low versus high) $(p=0.362)$, lymphovascular invasion $(p=0.178)$, perineural invasion $(p=0.778)$ or presence of mucinous neoplasm $(p=0.545)$. Moreover, S100A14 production did not correlate with age $(\mathrm{r}=0.121, p=0.222)$ or tumor diameter $(\mathrm{r}=-0.068, p=0.489)$. Table II summarizes the aforementioned results.

Comparison between the primary tumors and the liver metastases regarding S100A14 expression. S100A14 expression was lower in two out of three liver metastases when compared with the corresponding primary tumors, whereas it was higher in the third liver metastasis. However, the difference between primary (mean score \pm SD: $40 \pm 16.4$ ) and metastatic (mean score \pm SD: $33.1 \pm 21$ ) tumors was not statistically significant $(p=0.372)$.

Survival analysis according to S100A14 expression. The mean surveillance period was 50.4 months $(\mathrm{SD}=31.1)$ and the median surveillance period was 41 months (min-max: 1-99). There were available data concerning DSS for 81 patients, 22 of whom 


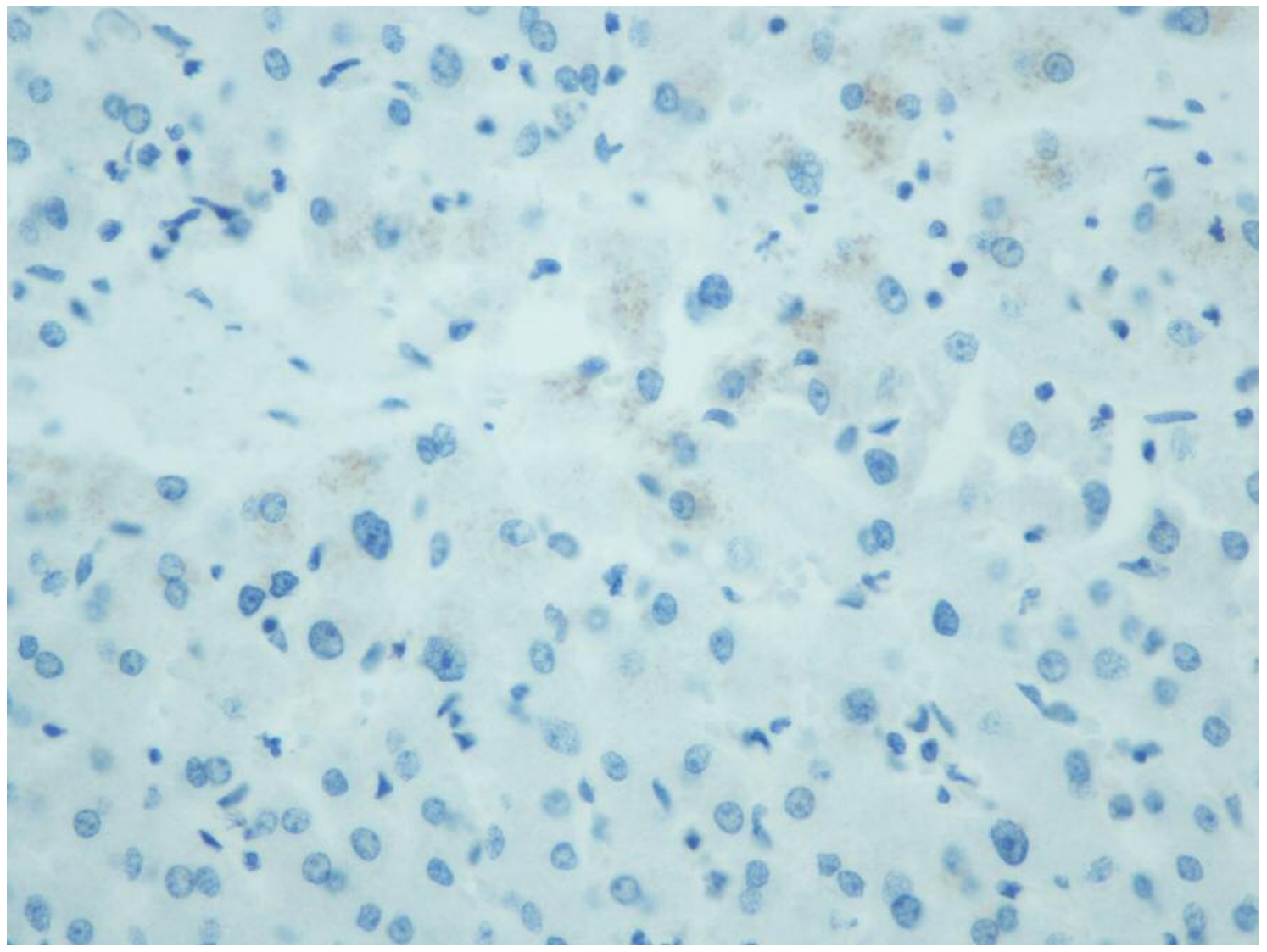

Figure 3. 3,3'diaminobenzidine (DAB) staining, representing S100A14 expression, in normal liver (400× original magnification).

(27.2\%) had died during the surveillance period. When the four groups with different S100A14 levels in the malignant tissues were compared, no significant differences were observed in regards to DSS [mean DSS (months) \pm SD: group 1: $66.7 \pm 8$, group 2: $81 \pm 7.9$, group 3: $71.9 \pm 6.3$, group 4: $73.3 \pm 9.3$ ] ( $p=0.643$ ) (Figure 4). However, the multivariate survival analysis showed that very high S100A14 expression in the malignant tissues (group $4 ;>75^{\text {th }}$ percentile) was an independent prognostic factor of shorter DSS $(\mathrm{HR}=3.584,95 \% \mathrm{CI}=1.029-12.49, \mathrm{~B}$ : 1.277, SE: 0.637 , Wald: $4.017, p=0.045$ ).

There were also available data regarding RFS for 76 patients, 24 of whom $(31.6 \%)$ had demonstrated relapse of their disease during the surveillance period. When the four groups with different S100A14 levels in the malignant tissues were compared, no significant differences were observed in regards to RFS [mean RFS (months) \pm SD: group 1: $70.3 \pm 8.4$, group 2: $78 \pm 8.2$, group 3: $64.7 \pm 7.9$, group 4: $63.3 \pm 10.2]$ ( $p=0.696)$ (Figure 5). However, the multivariate survival analysis showed that very high S100A14 expression in the malignant tissues (group $4 ;>75^{\text {th }}$ percentile) was an independent prognostic factor of shorter RFS $(\mathrm{HR}=4.527$,
95\% CI=1.511-13.561, B: 1.51, SE: 0.56, Wald: 7.275, $p=0.007)$. The results of the multivariate survival analysis are shown in Table III.

\section{Discussion}

Pietas et al. identified in 2002 a new gene located in the region of human chromosome 1q21 where the genes of most S100 proteins are clustered, which was named S10014. They managed to do this by analyzing a subtraction cDNA library of a human lung cancer cell line. The S100A14 gene has four exons and three introns with a total length of $2165 \mathrm{bp}$. The corresponding cDNA is 1067 bp in length, with a coding region predicting a protein of 104 amino acids. The encoded mRNA is present in several normal human epithelial tissues, such as colon, rectum, small intestine, stomach, ovary, uterus, prostate, breast, thyroid, lung and kidney, with the highest expression noted in colon, followed by rectum, stomach and thyroid. The subcellular localization of the S100A14 protein is cytoplasmic with a denser presence around the nucleus (10). 
Table II. Associations of S100A14 with various clinicopathological parameters.

\begin{tabular}{|c|c|c|c|}
\hline \multirow[b]{2}{*}{ Parameter } & \multicolumn{2}{|c|}{ Normal intestinal mucosa } & \multirow[b]{2}{*}{$p$-Value } \\
\hline & Mean score \pm SD & Median score (min-max) & \\
\hline \multicolumn{4}{|l|}{ Gender } \\
\hline Men & $46.2 \pm 9.4$ & $46(13.1-66.9)$ & 0.98 \\
\hline Women & $46.6 \pm 7.3$ & $46.4(32.5-62.9)$ & \\
\hline \multicolumn{4}{|l|}{ Age } \\
\hline$\leq 65$ years & $44.3 \pm 10.1$ & $44.8(13.1-65)$ & 0.24 \\
\hline$>65$ years & $47.3 \pm 7.9$ & $46.3(26-66.9)$ & \\
\hline \multicolumn{4}{|l|}{ Segment } \\
\hline Right & $47.5 \pm 10.1$ & $49.1(19.8-66.9)$ & 0.446 \\
\hline Left & $45.8 \pm 7.9$ & $46.1(13.1-62.9)$ & \\
\hline \multicolumn{4}{|c|}{ Malignant tissue } \\
\hline Parameter & Mean score \pm SD & Median score (min-max) & $p$-Value \\
\hline \multicolumn{4}{|l|}{ Gender } \\
\hline Men & $44.5 \pm 9.7$ & $44.2(21.2-68.9)$ & 0.963 \\
\hline Women & $44.4 \pm 11.7$ & $45.7(22.6-74.8)$ & \\
\hline \multicolumn{4}{|l|}{ Age } \\
\hline$\leq 65$ years & $44.1 \pm 12.1$ & $43.7(21.2-68.9)$ & 0.694 \\
\hline$>65$ years & $45 \pm 9.4$ & $45.7(24.4-74.8)$ & \\
\hline \multicolumn{4}{|l|}{ Segment } \\
\hline Right & $46.3 \pm 10.1$ & $46.3(24.4-74.8)$ & 0.254 \\
\hline Left & $43.8 \pm 10.6$ & $44.2(21.2-68.9)$ & \\
\hline \multicolumn{4}{|c|}{ Tumor diameter } \\
\hline$\leq 4 \mathrm{~cm}$ & $44.6 \pm 10.5$ & $44.6(21.2-74.8)$ & 0.912 \\
\hline$>4 \mathrm{~cm}$ & $44.4 \pm 10.5$ & $44.3(24-68.9)$ & \\
\hline \multicolumn{4}{|l|}{$\mathrm{T}$} \\
\hline Tis-T2 & $49.1 \pm 9.4$ & $47.9(32.7-74.8)$ & 0.001 \\
\hline $\mathrm{T} 3-\mathrm{T} 4$ & $42.1 \pm 10.2$ & $43.6(21.2-63.6)$ & \\
\hline \multicolumn{4}{|l|}{$\mathrm{N}$} \\
\hline N0-N1 & $45.7 \pm 10.3$ & $46.3(21.2-74.8)$ & 0.034 \\
\hline $\mathrm{N} 2$ & $40.7 \pm 10.3$ & $43.8(22.6-59.2)$ & \\
\hline \multicolumn{4}{|l|}{ M } \\
\hline M0 & $45.5 \pm 10.1$ & $45.5(25.9-74.8)$ & 0.019 \\
\hline M1 & $38.9 \pm 11.3$ & $40.1(21.2-55.1)$ & \\
\hline \multicolumn{4}{|l|}{ Grade } \\
\hline Low & $45 \pm 10.2$ & $44.7(22.6-74.8)$ & 0.362 \\
\hline High & $42.9 \pm 11.3$ & $43.8(21.2-63.6)$ & \\
\hline \multicolumn{4}{|c|}{ Lymphovascular invasion } \\
\hline No & $45.3 \pm 10.6$ & $46.1(21.2-74.8)$ & 0.178 \\
\hline Yes & $42.1 \pm 9.9$ & $41.5(24.4-62.9)$ & \\
\hline \multicolumn{4}{|c|}{ Perineural invasion } \\
\hline No & $44.4 \pm 10.2$ & $44.4(21.2-74.8)$ & 0.778 \\
\hline Yes & $45.4 \pm 14.1$ & $44.6(22.6-62.9)$ & \\
\hline \multicolumn{4}{|c|}{ Mucinous neoplasm } \\
\hline No & $44.3 \pm 10.4$ & $44.2(21.2-74.8)$ & 0.545 \\
\hline Yes & $46.7 \pm 12$ & $47.4(26.8-63.6)$ & \\
\hline
\end{tabular}

T: Direct extent of the primary tumor, N: degree of disease spread to regional lymph nodes, M: distant metastases.

The role of S100A14 has been investigated in several types of malignant diseases. First of all, there are several studies trying to identify how S100A14 is implicated in tumorigenesis by conducting experiments on cancer cell lines. However, it seems that S100A14 affects tumorigenic processes in a different way in different types of malignancies (13-27). In particular, S100A14 enhances proliferation and cell growth in breast (13), cervical (17), ovarian (18) and hepatocellular cancer (19), whereas it inhibits them in oral (23), esophageal (24) and urothelial cancer (27). In addition, 


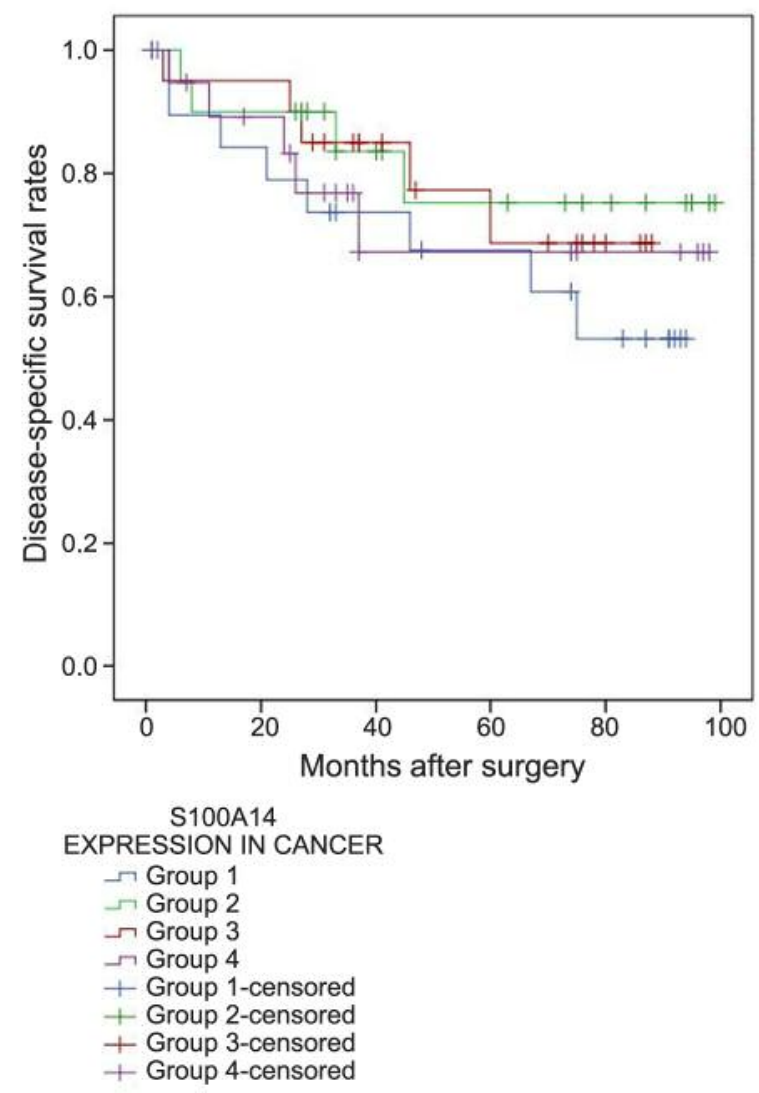

Figure 4. Disease-specific survival rates of patients with higher (group 4) and lower (groups 1,2,3) S100A14 expression in colorectal cancer.

S100A14 induces apoptosis in esophageal cancer (25). Furthermore, S100A14 facilitates cell migration in breast (1416), cervical (17), ovarian (18), hepatocellular (19) and lung cancer $(20,21)$, while it restrains it in gastric cancer (26). Similarly, under the influence of S100A14, motility is increased in breast cancer $(15,16)$, but decreased in urothelial cancer (27), and invasiveness is increased in breast (16), cervical (17), ovarian (18), hepatocellular (19) and lung cancer $(20,21)$, but decreased in oral (22) and gastric cancer (26). Finally, S100A14 seems to promote cell differentiation in esophageal (24) and gastric cancer (26), while it mediates epithelial-to-mesenchymal transition in cervical cancer (17). To sum up, S100A14 promotes tumorigenesis in breast, cervical, ovarian, hepatocellular and lung cancer (13-21), whereas it inhibits restrains it in oral, esophageal, gastric and urothelial cancer (22-27).

The aforementioned conclusion regarding the role of S100A14 is confirmed by clinical studies conducted on human malignant tissues (13-15, 17-21, 24, 26, 28-34). Concerning the comparison between normal and malignant tissues, S100A14 expression is higher in malignant tissues in breast $(13,19)$,

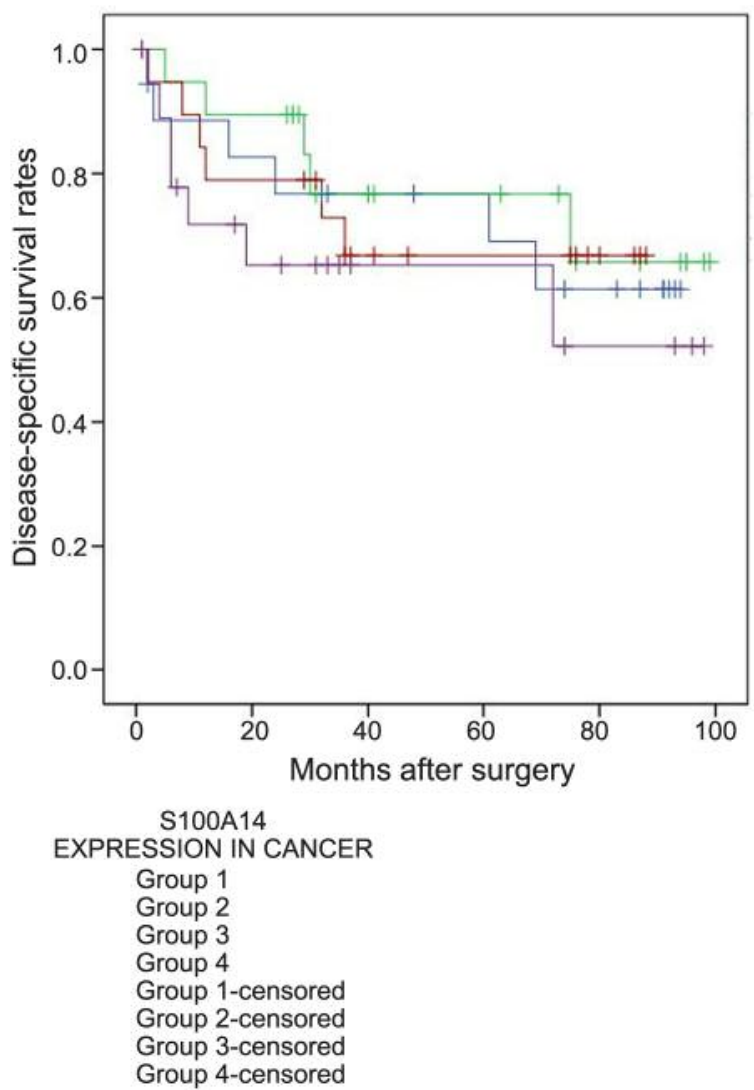

Figure 5. Relapse-free survival rates of patients with higher (group 4) and lower (groups 1, 2, 3) S100A14 expression in colorectal cancer.

ovarian (30), hepatocellular (19) and lung cancer (20), whereas it is lower in malignant tissues in colorectal cancer (34). As far as disease stage is concerned, high S100A14 levels are associated with advanced stages in cervical (17), ovarian (18), hepatocellular (19) and lung cancer $(20,21)$, while they are associated with early stages in small bowel cancer (33). In addition, S100A14 expression is increased as the depth of infiltration is increased in lung cancer (20), whereas the exact opposite is true for gastric cancer (26). Moreover, higher S100A14 levels are correlated to higher probability of lymph node metastasis in cervical (17) and lung cancer (20), but to lower probability of lymph node metastasis in gastric cancer (26). Similarly, increased production of S100A14 is associated with greater risk for distant metastases in lung cancer (21), but with reduced risk for distant metastases in gastric (26), small bowel (33) and colorectal cancer (34). In terms of tumor differentiation, S100A14 expression is higher in high-grade neoplasms in case of ovarian (18) and lung cancer $(20,21)$ and in low-grade neoplasms in case of esophageal (24), gastric (26, 32) and colorectal cancer (34). Finally, increased production of S100A14 is related to shorter survival in breast 
Table III. Multivariate survival analysis.

\begin{tabular}{|c|c|c|c|c|}
\hline \multirow{2}{*}{ Parameter } & \multicolumn{2}{|c|}{ Disease-specific survival } & \multicolumn{2}{|c|}{ Relapse-free survival } \\
\hline & HR $(95 \%$ CI $)$ & $p$-Value & HR $(95 \% \mathrm{CI})$ & $p$-Value \\
\hline Age $>65$ years & $6.321(1.586-25.191)$ & 0.009 & $6.369(1.967-20.621)$ & 0.002 \\
\hline Left-sided tumor & & 0.142 & $6.217(1.381-27.994)$ & 0.017 \\
\hline $\mathrm{T} 4$ & $3.607(1.081-12.032)$ & 0.037 & & 0.066 \\
\hline $\mathrm{N} 2$ & $8.46(2.683-26.678)$ & 0.0003 & $5.861(2.081-16.51)$ & 0.001 \\
\hline M1 & $4.386(1.351-14.242)$ & 0.014 & & 0.067 \\
\hline $\begin{array}{l}\text { Very high ( }>75 \text { th percentile) S100A14 } \\
\text { expression in malignant tissues }\end{array}$ & $3.584(1.029-12.49)$ & 0.045 & $4.527(1.511-13.561)$ & 0.007 \\
\hline
\end{tabular}

T: Direct extent of the primary tumor, $\mathrm{N}$ : degree of disease spread to regional lymph nodes, M: distant metastases.

$(13-15,28,29)$, ovarian $(18,31)$, hepatocellular (19) and lung cancer $(20,21)$, but to longer survival in gastric $(26,32)$ and colorectal cancer (34).

In the only other published study on colorectal cancer, Wang et al. found that S100A14 levels are lower in malignant tissues in comparison with normal tissues. Moreover, they detected lower rates of S100A14 expression in poorly differentiated tumors and cases with distant metastases, but no significant differences in terms of depth of infiltration (T) and lymph node metastases $(\mathrm{N})$. In addition, they reported worse survival in cases without S100A14 production (34). However, our results are somewhat differentiated from theirs. At this point we should mention that they used a monoclonal antibody against S100A14. This provided them with the advantage of reduced cross-reactivity, but also with the disadvantage of vulnerability to even slight changes in the only one epitope that the monoclonal antibody recognizes, leading to reduced binding capacity in that case. On the other hand, we used a polyclonal antibody against S100A14, having the disadvantage of somewhat higher cross-reactivity, but also the advantages of higher affinity, recognizing expression even in low levels, and more tolerance to minor antigen changes, due to the recognition of more than one epitopes (35). Moreover, whereas we tried to take into account both the intensity and the extent of S100A14 expression and combine them into a quantitative scale to be more accurate, Wang et al. were based only on the extent of S100A14 expression in a qualitative manner (with $30 \%$ of cells expressing S100A14 considered as cut-off point).

In our study, we observed a reduction in S100A14 expression in more advanced tumors (T3-T4, N2 and/or M1 cases), but we did not find any significant difference concerning histological grade. Nevertheless, very high S100A14 production was associated with shorter DSS and RFS. This may indicate that the reduction in S100A14 expression in advanced disease does not necessarily mean that S100A14 directly inhibits tumorigenic processes, but it is rather an indirect effect, and this protein enhances the tumor aggressiveness in cases that retain high levels of it. Unfortunately, the fact that there are no studies regarding the role of S100A14 in tumorigenesis of colorectal cancer on the molecular level does not allow us to draw safe conclusions.

Concerning potential future clinical applications, S100A14 could be used as prognostic marker and/or therapeutic target in colorectal cancer. A high S100A14 expression in malignant tissues detected in the immunohistochemical analysis of the surgical specimen could contribute into the categorization of patients as high-risk for disease recurrence and shorter survival, rendering them potential candidates for more aggressive adjuvant treatment. Furthermore, neutralizing antibodies (e.g. against S100A8/A9 and S100A4) and small molecule inhibitors (e.g. niclosamide against $\mathrm{S} 100 \mathrm{~A} 4$, amlexanox against S100A13 and cromolyn against S100P) against several S100 proteins have recently been developed and even tested in animal studies $(3,4)$. However, no agent against S100A14 specifically has been developed yet, but it could be an additional future target from the S100 family. Either way, it is of critical importance to conduct more clinical and experimental studies about the role of S100A14 in colorectal cancer, so that its potential clinical applications can be proved.

\section{Conflicts of Interest}

All the Authors declare that there are no conflicts of interest.

\section{Authors' Contributions}

Study design: AD, DM, IDK, GK; Study supervision: DM, NK, GK; Data collection: AD, IDK, GA, ZG; Data analysis: AD, IDK, GA, ZG; Statistical analysis: IDK; Manuscript preparation: AD, DM, IDK; Manuscript approval: all Authors.

\section{References}

1 Donato R, Cannon BR, Sorci G, Riuzzi F, Hsu K, Weber DJ and Geczy CL: Functions of S100 proteins. Curr Mol Med 13(1): 24-57, 2013. PMID: 22834835. 
2 Chen $\mathrm{H}, \mathrm{Xu} \mathrm{C}$, Jin Q and Liu Z: S100 protein family in human cancer. Am J Cancer Res 4(2): 89-115, 2014. PMID: 24660101.

3 Bresnick AR, Weber DJ and Zimmer DB: S100 proteins in cancer. Nat Rev Cancer 15(2): 96-109, 2015. PMID: 25614008. DOI: $10.1038 / \mathrm{nrc} 3893$

4 Bresnick AR: S100 proteins as therapeutic targets. Biophys Rev 10(6): 1617-1629, 2018. PMID: 30382555. DOI: 10.1007/ s12551-018-0471-y

5 Moravkova P, Kohoutova D, Rejchrt S, Cyrany J and Bures J: Role of S100 proteins in colorectal carcinogenesis. Gastroenterol Res Pract 2016: 2632703, 2016. PMID: 26880885. DOI: 10.1155/ 2016/2632703

6 Kuberappa PH, Bagalad BS, Ananthaneni A, Kiresur MA and Srinivas GV: Certainty of S100 from physiology to pathology. J Clin Diagn Res 10(6): ZE10-ZE15, 2016. PMID: 27504432. DOI: $10.7860 / J C D R / 2016 / 17949.8022$

7 Christensen MV, Høgdall C, Jensen SG, Lokman N, Ricciardelli C, Christensen IJ, Christiansen P, Brask J, Karlsen MA, Nissen TK, Jochumsen KM and Høgdall E: Annexin A2 and S100A10 as candidate prognostic markers in epithelial ovarian cancer Anticancer Res 39(5): 2475-2482, 2019. PMID: 31092442. DOI: 10.21873/anticanres.13367

8 Almatroodi SA, McDonald CF, Collins AL, Darby IA and Pouniotis DS: Quantitative proteomics of bronchoalveolar lavage fluid in lung adenocarcinoma. Cancer Genomics Proteomics 12(1): 39-48, 2015. PMID: 25560643.

9 Moris D, Damaskos C, Spartalis E, Papalampros A, Vernadakis S, Dimitroulis D, Griniatsos J, Felekouras E and Nikiteas N: Updates and critical evaluation on novel biomarkers for the malignant progression of intraductal papillary mucinous neoplasms of the pancreas. Anticancer Res 37(5): 2185-2194, 2017. PMID: 2847 6781. DOI: 10.21873/anticanres.11553

10 Pietas A, Schlüns K, Marenholz I, Schäfer BW, Heizmann CW and Petersen I: Molecular cloning and characterization of the human S100A14 gene encoding a novel member of the S100 family. Genomics 79(4): 513-522, 2002. PMID: 11944983. DOI: 10.1006/geno.2002.6744

11 Bosman FT: WHO Classification of Tumours of the Digestive System, 4th edn. World Health Organization. International Agency for Research on Cancer. Lyon, France: IARC Press, 2010

12 Brierley JD, Gospodarowicz MK, Wittekind C, editors: Colon and Rectum. In: TNM classification of malignant tumours, 8th ed. Oxford, UK: Wiley-Blackwell, pp. 73-76, 2016.

$13 \mathrm{Xu}$ C, Chen H, Wang X, Gao J, Che Y, Li Y, Ding F, Luo A, Zhang S and Liu Z: S100A14, a member of the EF-hand calcium-binding proteins, is overexpressed in breast cancer and acts as a modulator of HE2 signaling. J Biol Chem 289(2): 827837, 2014. PMID: 24285542. DOI: 10.1074/jbc.M113.469718

$14 \mathrm{He}$ H, Li S, Chen H, Li L, Xu C, Ding F, Zhan Y, Ma J, Zhang S, Shi Y, Qu C and Liu Z: 12-O-tetradecanoylphorbol-13-acetate promotes breast cancer cell motility by increasing S100A14 level in a Kruppel-like transcription factor 4 (KLF4)-dependent manner. J Biol Chem 289(13): 9089-9099, 2014. PMID: 24532790. DOI: $10.1074 /$ jbc.M113.534271

15 Tanaka M, Ichikawa-Tomikawa N, Shishito N, Nishiura K, Miura T, Hozumi A, Chiba H, Yoshida S, Ohtake T and Sugino T: Co-expression of S100A14 and S100A16 correlates with a poor prognosis in human breast cancer and promotes cancer cell invasion. BMC Cancer 15: 53, 2015. PMID: 25884418. DOI: $10.1186 / \mathrm{s} 12885-015-1059-6$
16 Chen H, Yuan Y, Zhang C, Luo A, Ding F, Ma J, Yang S, Tian Y, Tong T, Zhan Q and Liu Z: Involvement of S100A14 protein in cell invasion by affecting expression and function of matrix metalloproteinase (MMP)-2 via p53-dependent transcriptional regulation. J Biol Chem 287(21): 17109-17119, 2012. PMID: 22451655. DOI: $10.1074 /$ jbc.M111.326975

17 Wang X, Yang J, Qian J, Liu Z, Chen H and Cui Z: S100A14, a mediator of epithelial-mesenchymal transition, regulates proliferation, migration and invasion of human cervical cancer cells. Am J Cancer Res 5(4): 1484-1495, 2015. PMID: 26101712.

18 Cho H, Shin HY, Kim S, Kim JS, Chung JY, Chung EJ, Chun KH, Hewitt SM and Kim JH: The role of S100A14 in epithelial ovarian tumors. Oncotarget 5(11): 3482-3496, 2014. PMID: 24939856. DOI: $10.18632 /$ oncotarget.1947

19 Zhao FT, Jia ZS, Yang Q, Song L and Jiang XJ: S100A14 promotes the growth and metastasis of hepatocellular carcinoma. Asian Pac J Cancer Prev 14(6): 3831-3836, 2013. PMID: 23886191. DOI: 10.7314/apjcp.2013.14.6.3831

20 Katono K, Sato Y, Kobayashi M, Saito K, Nagashio R, Ryuge S, Igawa S, Nakashima H, Shiomi K, Satoh Y, Ichinoe M, Murakumo Y, Saegusa M and Masuda N: Clinicopathological significance of S100A14 expression in lung adenocarcinoma. Oncol Res Treat 40(10): 594-602, 2017. PMID: 28950283. DOI: 10.1159/000478100

21 Ding F, Wang D, Li XK, Yang L, Liu HY, Cui W, Liu ZH and Che YQ: Overexpression of S100A14 contributes to malignant progression and predicts poor prognosis of lung adenocarcinoma. Thorac Cancer 9(7): 827-835, 2018. PMID: 29733545. DOI: 10.1111/1759-7714.12654

22 Sapkota D, Bruland O, Costea DE, Haugen H, Vasstrand EN and Ibrahim SO: S100A14 regulates the invasive potential of oral squamous cell carcinoma derived cell-lines in vitro by modulating expression of matrix metalloproteinases, MMP1 and MMP9. Eur J Cancer 47(4): 600-610, 2011. PMID: 21074410. DOI: 10.1016/ j.ejca.2010.10.012

23 Sapkota D, Costea DE, Blø M, Bruland O, Lorens JB, Vasstrand EN and Ibrahim SO: S100A14 inhibits proliferation of oral carcinoma derived cells through G1-arrest. Oral Oncol 48(3): 219-225, 2012. PMID: 22032898. DOI: 10.1016/j.oraloncology. 2011.10 .001

24 Chen H, Ma J, Sunkel B, Luo A, Ding F, Li Y, He H, Zhang S, Xu C, Jin Q, Wang Q and Liu Z: S100A14: novel modulator of terminal differentiation in esophageal cancer. Mol Cancer Res 11(12): 1542-1553, 2013. PMID: 24107296. DOI: 10.1158/15417786.MCR-13-0317

25 Jin Q, Chen H, Luo A, Ding F and Liu Z: S100A14 stimulates cell proliferation and induces cell apoptosis at different concentrations via receptor for advanced glycation end products (RAGE). PLoS One 6(4): e19375, 2011. PMID: 21559403. DOI: 10.1371/journal.pone.001937

26 Zhu M, Wang H, Cui J, Li W, An G, Pan Y, Zhang Q, Xing R and Lu Y: Calcium-binding protein S100A14 induces differentiation and suppresses metastasis in gastric cancer. Cell Death Dis $8(7)$ : e2938, 2017. PMID: 28726786. DOI: 10.1038/cddis.2017.297

27 Lee MS, Hsu WT, Deng YF, Lin CW, Weng EY, Chang HP, Wu SF3 and Li C: SOX2 suppresses the mobility of urothelial carcinoma by promoting the expression of S100A14. Biochem Biophys Rep 7: 230-239, 2016. PMID: 28955911. DOI: 10.1016/ j.bbrep.2016.06.016 
28 Ehmsen S, Hansen LT, Bak M, Brasch-Andersen C, Ditzel HJ and Leth-Larsen R: S100A14 is a novel independent prognostic biomarker in the triple-negative breast cancer subtype. Int J Cancer 137(9): 2093-2103, 2015. PMID: 25912829. DOI: $10.1002 / \mathrm{ijc} .29582$

$29 \mathrm{Xu}$ CS, Chen HY, Lu CR and Liu ZH: Expression and regulatory mechanism of S100A14 in breast cancer. Zhonghua Zhong Liu Za Zhi 38(4): 252-257, 2016. PMID: 27087370. DOI: 10.3760/ cma.j.issn.0253-3766.2016.04.003

30 Qian J, Ding F, Luo A, Liu Z and Cui Z: Overexpression of S100A14 in human serous ovarian carcinoma. Oncol Lett 11(2): 1113-1119, 2016. PMID: 26893702. DOI: 10.3892/ol.2015.3984

31 Zhao H, Guo E, Hu T, Sun Q, Wu J, Lin X, Luo D, Sun C, Wang C, Zhou B, Li N, Xia M, Lu H, Meng L, Xu X, Hu J, Ma D, Chen G and Zhu T: KCNN4 and S100A14 act as predictors of recurrence in optimally debulked patients with serous ovarian cancer. Oncotarget 7(28): 43924-43938, 2016. PMID: 27270322. DOI: $10.18632 /$ oncotarget.9721

32 Zhang Q, Zhu M, Cheng W, Xing R, Li W, Zhao M, Xu L, Li E, Luo $\mathrm{G}$ and $\mathrm{Lu}$ Y: Downregulation of $425 \mathrm{G}>\mathrm{a}$ variant of calcium-binding protein S100A14 associated with poor differentiation and prognosis in gastric cancer. J Cancer Res Clin Oncol 141(4): 691-703, 2015. PMID: 25266115. DOI: 10.1007/ s00432-014-1830-0
33 Kim G, Chung JY, Jun SY, Eom DW, Bae YK, Jang KT, Kim J, Yu E and Hong SM: Loss of S100A14 expression is associated with the progression of adenocarcinomas of the small intestine. Pathobiology 80(2): 95-101, 2013. PMID: 23038644. DOI: 10.1159/000342394

34 Wang HY, Zhang JY, Cui JT, Tan XH, Li WM, Gu J and Lu YY; Expression status of S100A14 and S100A4 correlates with metastatic potential and clinical outcome in colorectal cancer after surgery. Oncol Rep 23(1): 45-52, 2010. PMID: 19956863.

35 Kurien BT and Scofield RH: Validating antibody specificities for immunohistochemistry by protein blotting methods. Methods Mol Biol 1554: 61-73, 2017. PMID: 28185183. DOI: 10.1007/ 978-1-4939-6759-9 3

Received October 16, 2019

Revised November 2, 2019

Accepted November 4, 2019 